\title{
Analysis of the Ground Adjustment Ability of Ground Source Heat Pump Systems during Intermittent Operation in Summer
}

\author{
LU Fenbao ${ }^{1, a^{*}}$, FU Yongzheng ${ }^{2, \mathrm{~b}}$ and SHI Lei $\mathrm{i}^{3, \mathrm{c}}$ \\ ${ }^{1}$ College of Urban Construction, Wuhan University of Science and Technology, Wuhan, China \\ ${ }^{2}$ College of Urban Construction, Wuhan University of Science and Technology, Wuhan, China \\ ${ }^{3}$ Zhejiang Loopmaster Energy Technology Co., Ltd., China \\ alufenbao_2013@126.com, b446965592qq.com, ${ }^{c} 176785813 q q . c o m$
}

\begin{abstract}
Keywords: Ground Source Heat Pump (GSHP); Ground Heat Exchanger (GHE); Intermittent Operation; Adjustment Ability

Abstract: Analyzes the ground adjustment ability in thermal equilibrium of the GSHP system during intermittent operation of $1: 1$ and 1:2 in summer through experiments. The result shows that the intermittent operation of 1:2 can maintain good heat transfer efficiency and better achieve restoration of the soil temperature field. For the intermittent operation of 1:1, however, the result of heat transfer of the GHE will become worse. It can be also concluded that through reasonable manual control in intermittent operation, strengthened heat transfer can help maintain the efficiency of heat pump units and better solve the problem of the soil thermal equilibrium. The conclusion can provide a good reference for running GSHP systems.
\end{abstract}

\section{Introduction}

GSHP system adopts shallow geothermal energy resources to meet air conditioning, heating, water heating and other demands for buildings. It has been more and more widely acknowledged as an important renewable energy technique. The key for the GSHP system lies in the study of the heat transfer performance of the GHE. Therefore, it's significantly important to fully understand the temperature field distribution around buried pipes and analyze the heat transfer mechanism of the GHE and factors affecting the heat transfer [1].

Compared with horizontal buried pipes, vertical buried pipes can be more suitable for Chinese engineering application as a result of saving areas. Meanwhile, many studies draw similar conclusions as follows: the GSHP system can be in long-term stable operation when the annual cumulative heat absorption in the GHE is equal to the annual cumulative heat release in that [2]. But in non-composite GSHP systems, it's merely a coincidence that the heat releases in summer and heat absorption in winter are exactly the same. More often they are not, that is, the continuous operation of GSHP systems can lead the soil temperature to change in one-way. In another point, however, soil temperature field is characteristic of self-adjusting so that intermittent operation can be applied to better improve the condition. This paper studies the change of the soil temperature field in vertical GHE systems during different intermittent operations in summer, the result of which may provide certain reference for design and start-stop control of GSHP systems.

\section{Experiment Platform}

The GSHP research base is located in the fifth building, which belongs to the college of urban construction of Wuhan University of Science and Technology. The terminals of the whole air conditioning system are mainly on the fifth floor of the building. The pipe-buried region of the ground-source side is located outdoors near the building. The manifold is set outside for inspection, while heat pump, water pump, central monitoring computer room and other equipment are set indoors on the first floor. 
The GSHP system, with air-conditioning area of $650 \mathrm{~m}^{2}$, consists of buried pipes of different diameters, spacing and forms of single and double U-tubes. As shown in Fig.1, the pipe-buried regions has 18 pipelines in total with each single hole of $100 \mathrm{~m}$ depth, and are divided into 4 small regions according to different pipe spacing. No.1 and No. 2 regions are arranged with 4 vertical pipelines in the square spacing of $3.5 \mathrm{~m} \times 3.5 \mathrm{~m}$ and $4.5 \mathrm{~m} \times 4.5 \mathrm{~m}$, respectively; No. 3 region with 8 vertical pipelines in the square spacing of $5 \mathrm{~m} \times 5 \mathrm{~m}$; No.4 region is not shown for it's beyond the scope of this paper.

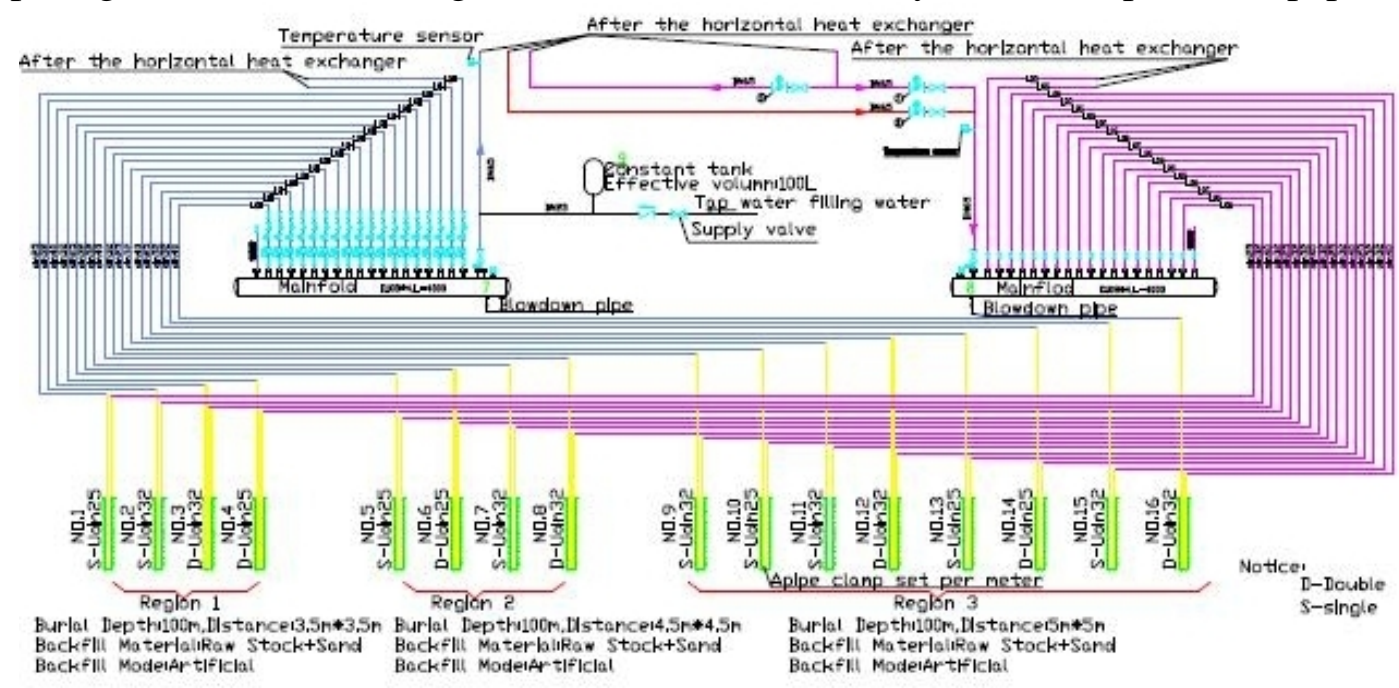

Fig.1 The vertical buried pipe system diagram

\section{Experimental Schemes}

\section{Analysis of experimental scheme}

The main test data is the water temperature of buried pipes, whose measuring points are arranged as shown in Fig.2. The corresponding points are in $10 \mathrm{~m}, 20 \mathrm{~m}, 40 \mathrm{~m}, 60 \mathrm{~m}, 80 \mathrm{~m}$ and $100 \mathrm{~m}$ depth.

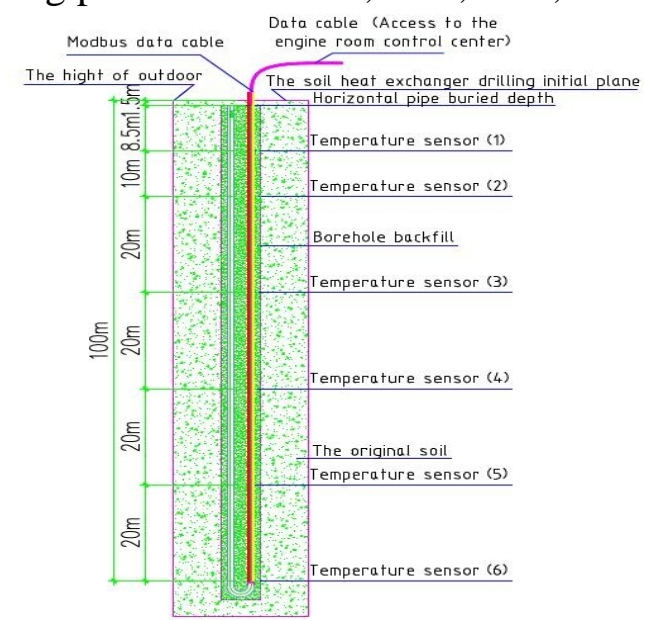

Fig.2 Layout diagrams of temperature measuring points on vertical pipes

This experiment, which conducted in the cycle of 24 hours from July to August in 2014, is manually controlled during intermittent operations of $1: 1$ and 1:2 to analyze the soil temperature field restoration in the period of 3 days, respectively.

\section{Analysis of buried pipes' temperature changes of each measuring point}

From the temperature changes shown in Fig.3, the intermittent operation of 1:1 makes it slow to restore the ground temperature. After the 1st operation cycle, the temperature difference between some certain points and their initial states is as high as $1.3{ }^{\circ} \mathrm{C}$. With the unit continuing running in the next 12 hours(in the 2 nd operation cycle), the temperature difference increases. This can degrade the unit operation performance and even cause the unit to work improperly. On the other hand, after 
intermittent downtime of each cycle, the deeper the drilling is, the smaller the temperature difference becomes, which does good to the heat transfer of the next cycle.

From the temperature changes shown in Fig.4, it can be concluded that, after the 1st operation cycle, the largest temperature difference between some certain points and their initial states is $0.4{ }^{\circ} \mathrm{C}$, which hardly affect the unit operation performance. In addition, as with one of the conclusions drawn in Fig.3, heat transfer between buried pipes and soil tends to vary gently when the temperature difference becomes smaller with the drilling getting deeper after intermittent downtime of each cycle.

As suggested above, when heat pump units are in operation, the underground soil temperature near the borehole wall increases. The temperature rises faster in the first cycle than in the subsequent cycle. This is because the temperature difference between buried pipes and soil is larger at the beginning of the unit operation. With the continuation of the unit operation, the temperature difference decreases and the heat transfer weakens. Eventually, the temperature changes flatten. Furthermore, the heat transfer performance of buried pipes can be effectively improved with adopting the intermittent operation mode. So the longer downtime lasts, namely, the longer soil temperature field returns to the original state, the better heat transfer condition becomes. But economical efficiency should be taken into consideration correspondingly.

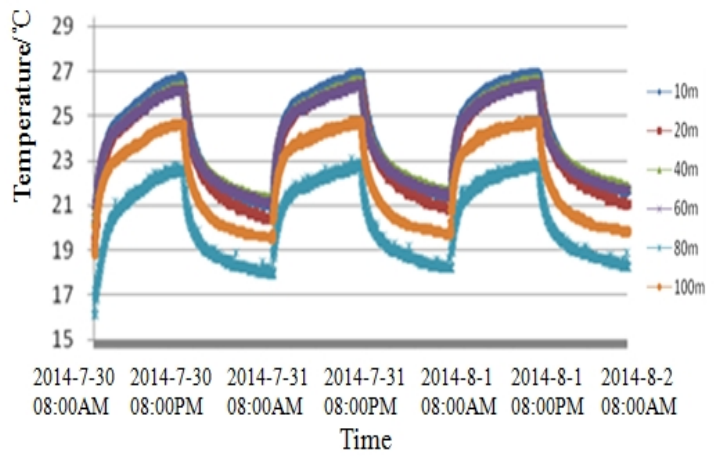

Fig.3 Temperature changes of each measuring point (No.2 buried pipe) during the intermittent operation of $1: 1$

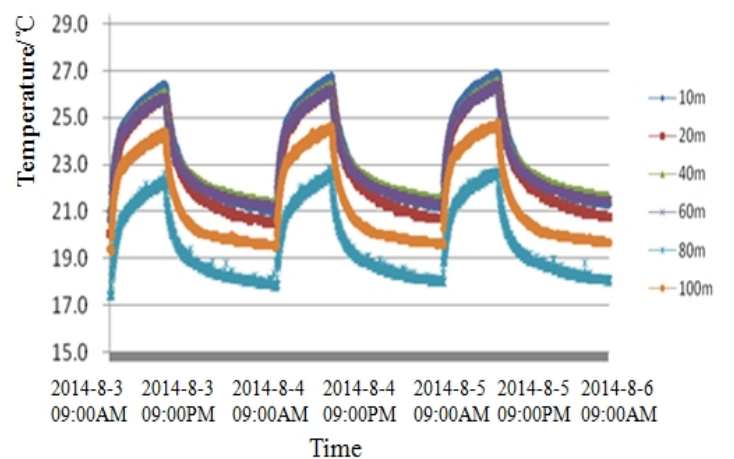

Fig.4 Temperature changes of each measuring point (No.2 buried pipe) during the intermittent operation of $1: 2$

\section{Water temperature changes between import and export of heat pump units}

In order to guarantee heat pump units working properly, its export water temperature should be below $30{ }^{\circ} \mathrm{C}$. When the temperature exceeds, heat pump units will stop running. As shown in Fig. 5 \& Fig.6, export water temperature is always below $30{ }^{\circ} \mathrm{C}$ during both intermittent operations, which certainly has good effects on heat pump operation.

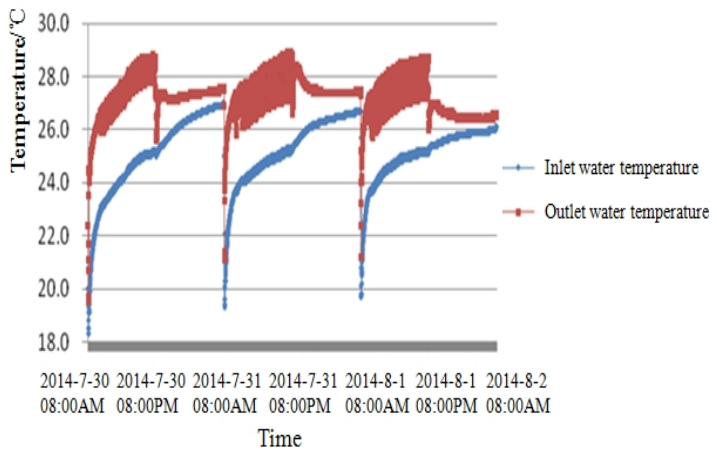

Fig.5 Water temperature changes between import and export of heat pump units during the intermittent operation of $1: 1$

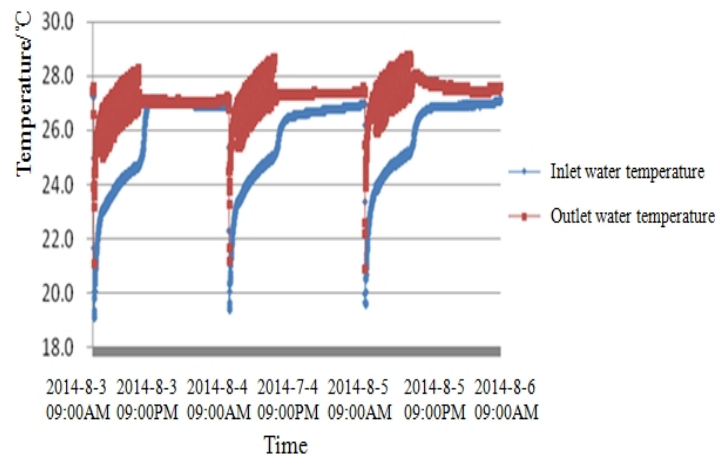

Fig.6 Water temperature changes between import and export of heat pump units during the intermittent operation of 1:2

\section{Heat release of heat pump units from GHE to the ground}

Due to the heat release of the GHE, soil temperature field changes. The temperature difference between buried pipes and soil is larger at the beginning of the unit operation, thus rapidly increasing heat release and soil temperature, as shown in Fig. 7 \& Fig.8. 
In Fig.7, the corresponding tangent slopes decrease gradually in each operation cycle. Heat exchange capacity of the GHE is about $32.5 \mathrm{~W} / \mathrm{m}$ in the 1 st operation cycle, while it's about $31.7 \mathrm{~W} / \mathrm{m}$ and $30 \mathrm{~W} / \mathrm{m}$ in the next two cycles, that is, falling by $2.5 \%$ and $7.7 \%$, respectively. In this case, the soil temperature will rise and inevitably affect the heat transfer between soil and the GHE, which can get worse and eventually have bad effects on the efficiency of heat pump units.

In Fig.8, the corresponding tangent slopes are nearly the same in each operation cycle. Heat exchange capacity of the GHE is about $32.5 \mathrm{~W} / \mathrm{m}$ in 3 continuous operation cycles. In this case, heat transfer process can be enhanced, which helps maintain the efficiency of heat pump units and better solve the problem of the soil thermal equilibrium.

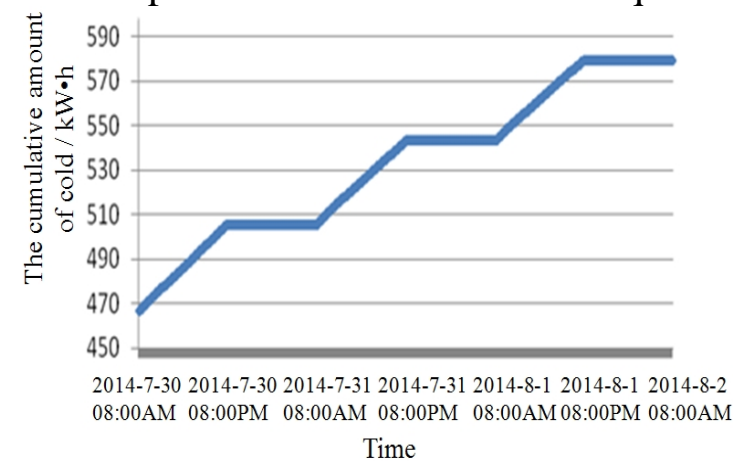

Fig.7 Cumulative cooling capacity change of the No.1 buried pipe during intermittent operation of $1: 1$

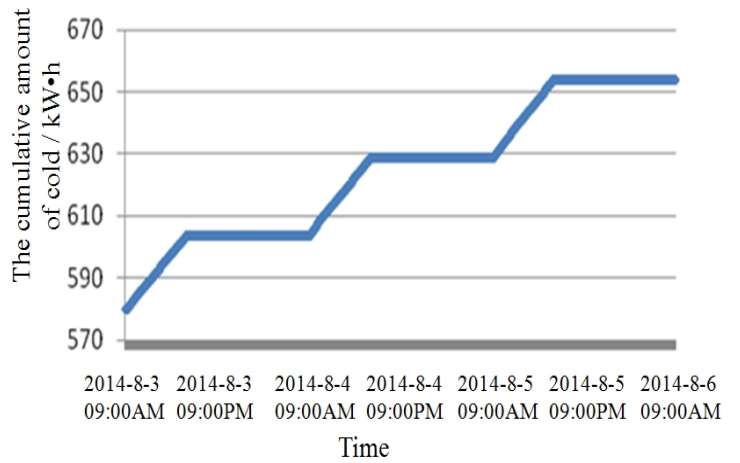

Fig.8 Cumulative cooling capacity change of the No.1 buried pipe during intermittent operation of $1: 2$

\section{Conclusions}

Analyzes the change of the soil temperature field in the vertical GSHP system during different intermittent operations in summer through experiments. Conclusions as follows:

(1) By reasonable manual control of intermittent operation, strengthened heat transfer can help maintain the efficiency of heat pump units and better solve the problem of the soil thermal equilibrium.

(2) The main heat transfer between buried pipes and soil tends to vary gently with the increase in depth of buried pipes.

(3) As is suggested in this paper, heat exchange capacity of the GHE generally remains the same during intermittent operation of 1:2, namely, heat transfer of the GHE is "the best" in this case. During intermittent operation of 1:1, however, the soil temperature increases and the heat exchange capacity of the GHE decreases by $7.7 \%$ in 3 days, which in turn has bad effects on the efficiency of heat pump units.

\section{References}

[1] Wang Junjie, Xu Yutang, Mao Jiani: submitted in Chinese to Heating, Ventilation \& Air Conditioning (2009)

[2] Hao He, Zhang Sufang, Li Yan, Shi Yong: submitted in Chinese to Heating, Ventilation \& Air Conditioning (2014) 